\title{
Atividade antioxidante e antimicrobiana in vitro de extratos de caqui (Diospyros kaki L.) cultivar Rama Forte
}

\author{
In vitro antioxidant and antimicrobial properties of \\ persimmon (Diospyros kaki L. cv. Rama Forte) extracts
}

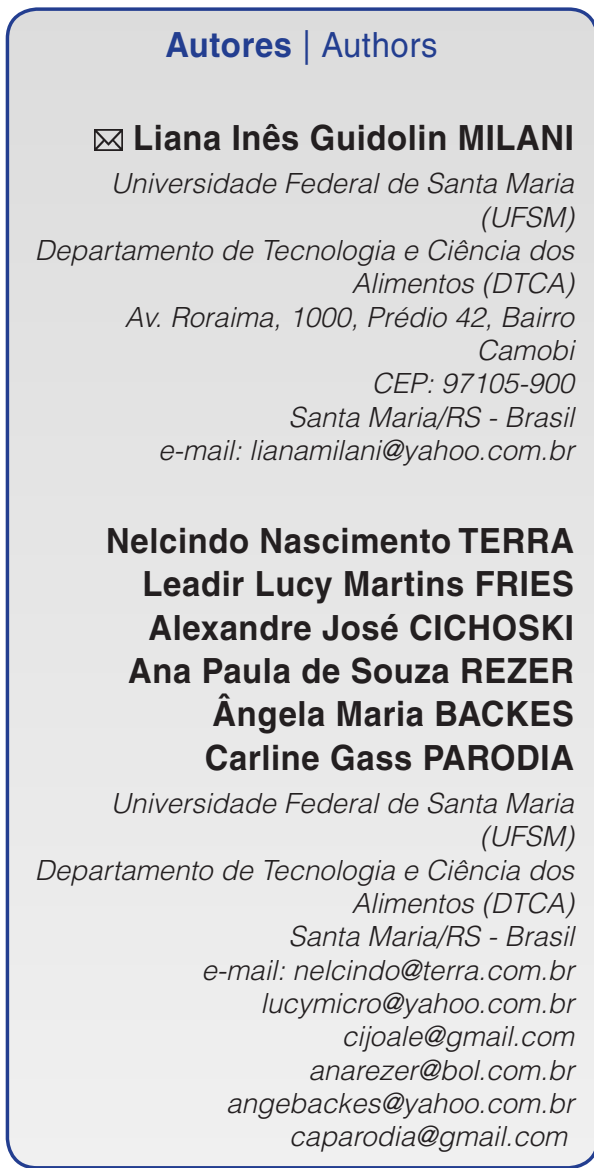

$\triangle$ Autor Correspondente / Corresponding Author

Recebido / Received: 27/04/2011 Aprovado / Approved: 29/11/2011 Publicado / Published: jun./2012

\section{Resumo}

Atualmente, as atividades antioxidante e antimicrobiana de vários compostos fenólicos e de extratos de plantas têm sido avaliadas em muitos experimentos. O objetivo deste estudo foi elaborar o extrato hidroetanólico bruto de caqui (Diospyros kaki L.) cultivar Rama Forte e fracioná-lo empregando solventes com diferentes polaridades, para posteriormente determinar os compostos fenólicos totais e verificar as atividades antioxidante e antimicrobiana in vitro tanto do extrato hidroetanólico bruto de caqui como das frações hexânica, clorofórmica, de acetato de etila e da fração residual, obtidas a partir do mesmo. Os compostos fenólicos totais foram determinados pelo método de Folin-Ciocalteu; a atividade antioxidante, por meio do método da captura do radical livre 2,2-difenil-1picrilidrazila (DPPH), e a atividade antimicrobiana pelo método de difusão em disco. O teor de compostos fenólicos do extrato hidroetanólico bruto de caqui, da fração residual, da fração acetato de etila, da fração hexânica e da fração clorofórmica foram de 1.277,94, 1.231,23, 37,24, 17,60 e 11,48 mg GAE.100 mL-1, respectivamente. O extrato hidroetanólico bruto de caqui e a fração residual apresentaram maior teor de compostos fenólicos e maior atividade antirradical frente ao DPPH do que as demais frações testadas, com valores de $1 \mathrm{C}_{50}$ de 0,2467 e 0,2567 mg. $\mathrm{mL}^{-1}$, respectivamente. O extrato de caqui e as frações não apresentaram atividade antimicrobiana in vitro sobre os microrganismos testados. Os resultados demonstraram que o extrato hidroetanólico bruto de caqui cv. Rama Forte e a fração residual contêm quantidade suficiente de compostos fenólicos capaz de contribuir positivamente na atividade antioxidante.

Palavras-chave: Caqui; Diospyros kaki L.; Atividade antioxidante; Atividade antimicrobiana; Compostos fenólicos.

\section{Summary}

The antioxidant and antimicrobial properties of various phenolic compounds and plant extracts have been evaluated in many experiments. The aim of this study was to obtain a crude hydroethanolic extract of persimmon (Diospyros kaki L.) CV. Rama Forte and fraction it using solvents with different polarities. Subsequently the total phenolic compounds and in vitro antioxidant and antimicrobial activities were determined in the crude hydroethanolic extract of persimmon, as well as in the hexane, chloroform, ethyl acetate and residual fractions obtained from it. The total phenolic compounds were determined by the Folin-Ciocalteau method, the antioxidant activity by the free radical scavenging 2,2-diphenyl-1-picrylhydrazyl (DPPH) method, and the antimicrobial activity by the disc diffusion method. The phenolic compound contents of the crude hydroethanolic extract of persimmon cv. Rama Forte, the residual aqueous fraction, ethyl acetate fraction, hexane fraction and chloroform fraction were, respectively, 1277.94, 1231.23, 37.24, 17.60 and $11.48 \mathrm{mg}$ GAE. $100 \mathrm{~mL}^{-1}$. The crude hydroethanolic extract of persimmon cv. Rama Forte and the residual fraction showed the highest contents of phenolic compounds and highest anti-radical activities against DPPH, as compared to the other fractions tested, with $\mathrm{IC}_{50}$ values of 0.2467 and $0.2567 \mathrm{mg} \cdot \mathrm{mL}^{-1}$, respectively. The persimmon extract and fractions showed no in vitro antimicrobial activity against the microorganisms tested. The results showed that the crude hydroethanolic extract of persimmon cv. Rama Forte and the residual fraction contained sufficient amounts of phenolic compounds to contribute positively to the antioxidant activity.

Key words: Persimmon; Diospyros kaki L.; Antioxidant activity; Antimicrobial activity; Phenolic compounds. 


\section{Introdução}

Vários estudos têm evidenciado os potenciais antioxidante e antimicrobiano de uma grande variedade de frutas e de vegetais (TAGURI et al., 2006; ASOLINI et al., 2006). O consumo frequente de frutas e vegetais tem sido associado à baixa incidência de doenças degenerativas, tais como câncer, doenças cardíacas, inflamatórias e do sistema imunológico, além de disfunções neurológicas e de cataratas. Esses fatos estão relacionados com a presença de vários compostos antioxidantes nas frutas e nos vegetais (WANG et al., 1997; FOGLIANO et al., 1999).

Os antioxidantes têm como função impedir que os radicais livres danifiquem as células e os tecidos (FOGLIANO et al., 1999). Na indústria alimentícia, o uso de antioxidantes não é recente; no entanto, nota-se uma tendência em substituir antioxidantes artificiais por naturais (AMAROWICZ et al., 2004).

As principais classes de antioxidantes que podem estar presentes naturalmente nos alimentos são os compostos fenólicos (ácidos fenólicos, flavonoides e taninos), carotenoides, tocoferóis, ácido ascórbico e seus derivados (VELIOGLU et al., 1998; AMAROWICZ et al., 2004). Os compostos fenólicos têm recebido muita atenção nos últimos anos, sobretudo por inibirem a peroxidação lipídica e a lipoxigenase in vitro (SOUSA et al., 2007). A ação desses antioxidantes pode ocorrer por meio de oxiredução, em que eles próprios seriam os reagentes, ou por interação com metais de transição $\left(\mathrm{Fe}^{+2}\right.$ e $\left.\mathrm{Cu}^{+2}\right)$. Os polifenóis são efetivos doadores de hidrogênio e seu potencial antioxidante está correlacionado com o número e a posição dos grupos hidroxílicos e conjugações, assim como com a presença de elétrons doadores no anel aromático $\mathrm{B}$, por causa da capacidade que esse anel aromático tem de suportar o despareamento de elétrons localizado no sistema de elétrons $\pi$ (RAMIREZTORTOZA et al., 2001).

A atividade antibacteriana de vários polifenóis e extratos de plantas também foi avaliada em estudos farmacêuticos e em alimentos (TAGURI et al., 2006; AHN et al., 2007). Alguns compostos fenólicos tais como os de sálvia, alecrim, tomilho, lúpulo, coentro, chá, cravo e manjericão são conhecidos por possuírem efeitos antimicrobianos contra patógenos alimentares (AHN et al., 2007).

O caqui é uma fruta que contém alto teor de polifenóis, incluindo flavonoides, ácido gálico, ácido p-cumárico, catequinas e taninos condensados; dessa forma, vários pesquisadores têm se dedicado ao estudo de suas propriedades antioxidantes (GORINSTEIN et al., 2001; PARK et al., 2006; GU et al., 2008; CHEN et al., 2008; MILANI et al., 2010) e antimicrobianas (MILANI et al., 2009).
Baseando-se nesses fatores, este experimento se propôs a elaborar o extrato hidroetanólico bruto de caqui cv. Rama Forte, depois fracioná-lo utilizando-se solventes com diferentes polaridades, visando uma semipurificação das substâncias presentes no extrato por meio de suas polaridades. Posteriormente, determinar os compostos fenólicos totais, as atividades antioxidante e antimicrobiana in vitro do extrato hidroetanólico bruto de caqui, bem como das frações hexânica, clorofórmica, de acetato de etila e da fração residual, sendo estas obtidas a partir do referido extrato.

\section{Material e métodos}

\subsection{Obtenção dos extratos}

Caquis (Diospyros kaki L.) da cultivar Rama Forte, provenientes de um pomar comercial de Nova Pádua-RS, foram colhidos em março de 2010. Foi utilizada uma caixa de caqui contendo 12 quilos, que foram desidratados em estufa com circulação de ar forçada a $60^{\circ} \mathrm{C}$ por 48 horas e, posteriormente, foram reduzidos a pó. O preparo do extrato hidroetanólico bruto de caqui e seu fracionamento com solventes de polaridade crescente foram realizados conforme descrição de Milani et al. (2009). Para o preparo do extrato hidroetanólico bruto de caqui, foi utilizada solução hidroetanólica (etanol 80\%) e caqui, na proporção de $20 \%$. Foram preparados $150 \mathrm{~mL}$ de extrato hidroetanólico bruto de caqui, que foram divididos em duas partes, sendo que uma das partes foi utilizada para os testes de determinação da atividade antimicrobiana, da atividade antioxidante e dos compostos fenólicos totais e a outra parte foi utilizada para o fracionamento. A partir da mesma amostra de caqui desidratado, foram elaborados três extratos hidroetanólicos brutos, que foram submetidos ao fracionamento separadamente. $\mathrm{Na}$ etapa do fracionamento, o extrato hidroetanólico bruto de caqui foi extraído inicialmente com n-hexano, depois com clorofórmio e com acetato de etila, seqüencialmente, originando as frações hexânica, clorofórmica, de acetato de etila e o resíduo, que foi considerado a fração residual. Após a obtenção das frações, o solvente foi totalmente eliminado em rotaevaporador (Fisatom ${ }^{\circledR} 802$ ) com vácuo de $-760 \mathrm{mmHg}$ e temperatura da água do banho a $44^{\circ} \mathrm{C}$ $\left( \pm 1^{\circ} \mathrm{C}\right)$ e a parte sólida remanescente foi resuspensa em água destilada esterilizada. O extrato hidroetanólico bruto e as frações assim que obtidas foram colocados em frascos de vidro âmbar ao abrigo da luz e mantidos a $4{ }^{\circ} \mathrm{C}\left( \pm 1^{\circ} \mathrm{C}\right)$ até o momento de serem utilizados para a determinação de compostos fenólicos totais e atividades antioxidante e antimicrobiana in vitro.

\subsection{Determinação de compostos fenólicos totais}

Para determinar os compostos fenólicos totais do extrato hidroetanólico bruto e das quatro frações 
(hexânica, clorofórmica, acetato de etila e residual), utilizou-se o método de Folin-Ciocalteu descrito por Singleton et al. (1999). As amostras foram diluídas com água destilada e filtradas em papel filtro qualitativo com gramatura de $80 \mathrm{~g} \cdot \mathrm{m}^{-2}$. Misturou-se 0,5 mL desse filtrado com 2,5 $\mathrm{mL}$ de reagente de Folin-Ciocalteu 0,2 N e, após $5 \mathrm{~min}$, adicionaram-se $2 \mathrm{~mL}$ de solução de carbonato de sódio (75 g.L $\left.\mathrm{L}^{-1}\right)$. Após repouso de $2 \mathrm{~h}$ em temperatura ambiente, a absorbância foi medida a 760 nm contra o branco, que consistiu de metanol. A absorbância da amostra foi comparada com a curva padrão de ácido gálico (concentrações de 0 a 15 mg de ácido gálico.100 $\mathrm{mL}^{-1}$ ) e aplicou-se a Equação 1:

$Y=0,1247 X+0,0334$

na qual $Y=$ absorbância, $X=$ concentração e $R^{2}=0,9986$. O conteúdo total de fenólicos foi expresso em mg equivalente de ácido gálico por $100 \mathrm{~mL}$ de extrato (mg GAE.100 mL-1). Foram realizadas três repetições, para a determinação de compostos fenólicos totais dos três extratos hidroetanólicos brutos de caqui elaborados e das respectivas frações, sendo os dados submetidos à análise de variância (ANOVA), e comparados pelo teste de Tukey, a 5\% de significância (COSTA NETO, 1977).

\subsection{Determinação da atividade antioxidante in vitro}

A atividade antioxidante foi avaliada por meio da capacidade de sequestro de radicais livres 2,2-difenil1-picril-hidrazil (DPPH), pelo extrato hidroetanólico bruto e pelas quatro frações em diferentes concentrações, utilizando-se a metodologia descrita por Gaio (2008) com algumas modificações. Utilizou-se o espectrofotômetro SP-220 da marca Biospectro e as leituras foram realizadas a $517 \mathrm{~nm}$. Incubaram-se durante $10 \mathrm{~min} 5 \mathrm{~mL}$ de soluções contendo concentrações crescentes dos extratos e das quatro frações em teste com $5 \mathrm{~mL}$ de uma solução etanólica de DPPH 0,1 mM. As diluições dos extratos e das frações foram realizadas em etanol $80 \%$. Procedeu-se da mesma maneira para a preparação da solução denominada "controle", porém substituíram-se $5 \mathrm{~mL}$ da amostra diluída por $5 \mathrm{~mL}$ de solvente (etanol 80\%). Para a solução denominada "branco", utilizou-se etanol 80\% e a amostra em cada concentração a ser testada, visando-se minimizar a interferência de componentes dos extratos na leitura (CHOI et al., 2002).

O porcentual de captação do radical DPPH foi calculado em termos de porcentagem e expresso como atividade antioxidante (AA\%), conforme a Equação 2:

$A A(\%)=100-\left\{\left[\left(\right.\right.\right.$ Abs. $_{\text {amostra }}-$ Abs $\left.\left._{\text {branco }}\right) \times 100\right] /$ Abs. $\left._{\text {controle }}\right\}$

Os resultados foram plotados em gráfico de atividade antioxidante (AA\%) versus concentração e os valores de $\mathrm{IC}_{50}$ (concentração dos extratos ou das frações em teste necessária para capturar $50 \%$ do radical livre
DPPH); estimados de acordo com a equação da curva, baseada em modelo sigmoidal (PEREIRA, 2009). O extrato oleoso de alecrim (Tasteguard, código/GIN 699994, Chr. Hansen $^{\circledR}$ ), que é um antioxidante natural empregado em alimentos, foi utilizado neste experimento como controle positivo, nas mesmas concentrações das amostras em teste. As análises foram realizadas em triplicata nas três repetições do extrato hidroetanólico bruto de caqui elaborado e nas respectivas frações obtidas. Os valores do gráfico foram apresentados como média ( \pm desvio padrão). Os valores de $I_{50}$ foram submetidos à análise de variância (ANOVA) e comparados pelo teste de Tukey, a 5\% de significância (COSTA NETO, 1977).

\subsection{Determinação da atividade antimicrobiana in vitro}

O extrato hidroetanólico bruto de caqui e as frações obtidas do referido extrato foram individualmente testados contra Staphylococcus aureus ATCC 25923, Bacillus cereus ATCC14579, Salmonella enterica subsp. enterica serovar Enteritidis ATCC 13076, Salmonella enterica subsp. enterica serovar Choleraesuis ATCC 10708, Salmonella enterica subsp. enterica serovar Typhimurium ATCC 14028, Pseudomonas aeruginosa ATCC10145, Escherichia coli ATCC 25922, Enterococcus faecalis ATCC 19433 e Enterobacter aerogenes ATCC 13048. Foi realizado o teste de difusão em disco, conforme os procedimentos descritos pelo Nacional Committee for Clinical Laboratory Standards (NCCLS, 2003). A partir de culturas recentes dos microrganismos em teste, foi preparada suspensão em solução fisiológica estéril ( $\mathrm{NaCl}$ 0,85\%), a qual foi padronizada para 0,5 da escala Mac Farland. As suspensões foram semeadas na superfície do Ágar Müller-Hinton, em placas de Petri, com auxílio de swab estéril. Posteriormente, discos de papel, com $6 \mathrm{~mm}$ de diâmetro, foram impregnados com $10 \mu \mathrm{L}$ do extrato ou fração em teste e plaqueados no ágar previamente inoculado com o microrganismo teste. Para controle negativo, os discos de papel foram embebidos em água destilada esterilizada e, para o controle positivo, foram usados discos com $30 \mu \mathrm{g}$ de cloranfenicol. Após 24 h de incubação a $36{ }^{\circ} \mathrm{C}$, foi medido o diâmetro dos halos de inibição de crescimento nas placas.

\section{Resultados e discussão}

O extrato hidroetanólico bruto de caqui e a fração residual apresentaram valores de compostos fenólicos de 1.277,94 e 1.231,23 mg GAE. $100 \mathrm{~mL}^{-1}$, respectivamente; estes não diferiram significativamente entre si, mas foram significativamente superiores aos valores de compostos fenólicos das frações obtidas com o n-hexano, o clorofórmio e o acetato de etila (Tabela 1).

A fração hexânica, a fração clorofórmica e a de acetato de etila apresentaram valores de 17,60, 11,48 e 
37,24 mg GAE.100 mL $\mathrm{mL}^{-1}$, respectivamente, e não diferiram significativamente entre si (Tabela 1). A fração hexânica e a clorofórmica foram as que apresentaram os menores valores de compostos fenólicos, provavelmente em razão das características apolares desses solventes, que lhes conferem menor afinidade pelos compostos fenólicos (SIMÕES et al., 2001).

O teor de compostos fenólicos apresentou-se mais elevado na fração residual e no extrato hidroetanólico bruto, o que significa que a maioria dos compostos fenólicos presentes no extrato hidroetanólico bruto de caqui não apresenta solubilidade nos solventes n-hexano, clorofórmio e acetato de etila utilizados no fracionamento, permanecendo na fração residual. Segundo Caetano et al. (2009), a solubilidade dos compostos fenólicos em um determinado solvente é uma característica peculiar da composição química da planta ou da fruta, o que explica a inexistência de um procedimento universal padrão, apontando para a necessidade de seleção criteriosa do método de extração para cada fonte natural de antioxidante.

Os teores de compostos fenólicos do extrato hidroetanólico bruto de caqui cultivar Rama Forte e das quatro frações foram maiores do que os obtidos por Milani et al. (2009), que elaboraram extrato hidroalcoólico bruto de caqui cultivar Quioto, cujo teor de compostos fenólicos foi de 232,12 mg GAE.100 mL-1. Após fracioná-lo, com o emprego dos mesmos solventes e procedimentos utilizados neste experimento, os autores verificaram que a fração residual apresentou valor de 187,35 mg GAE. $100 \mathrm{~mL}^{-1}$, seguida pela fração acetato de etila $\left(28,88 \mathrm{mg} \cdot \mathrm{mL}^{-1}\right)$, pela fração clorofórmica $(4,75 \mathrm{mg}$. $\left.\mathrm{mL}^{-1}\right)$ e pela fração hexânica $\left(2,09 \mathrm{mg} \cdot \mathrm{mL}^{-1}\right)$. Embora não tenham ocorrido diferenças nas metodologias utilizadas no processo de extração nos dois experimentos para elaboração dos extratos de caqui (cv. Rama Forte e cv. Quioto), os diferentes teores de compostos fenólicos encontrados estariam relacionados à cultivar, uma vez que, comparativamente, as cultivares não adstringentes de caquis parecem ter muito menos polifenóis, catequinas e taninos do que os tipos adstringentes (KATSUBE et al., 2004; SUZUKI et al., 2005; VEBERIC et al., 2010).

Vários estudos têm reportado a relação entre o conteúdo de compostos fenólicos e a atividade antioxidante de produtos vegetais (VELIOGLU et al., 1998; KATSUBE et al., 2004; CHEN et al., 2008). Park et al. (2006) observaram elevada correlação entre o conteúdo de compostos polifenólicos encontrados em extratos de caqui (Diospyros kaky L. var. Triumph) e a porcentagem de inibição da oxidação por meio do teste de captura de radicais livres DPPH. Tais resultados concordam com os obtidos no presente experimento, uma vez que o extrato oleoso de alecrim, o extrato hidroetanólico bruto de caqui e a fração residual, que apresentaram os maiores teores de compostos fenólicos, também apresentaram a maior atividade antioxidante e, consequentemente, apresentaram os menores valores de $I_{50}$ (Tabela 1 ; Figura 1).

Rosso (2006) verificou diminuição da atividade antirradical à medida que os extratos de acerola e açaí foram sendo purificados, apresentando também correlação direta com a diminuição dos teores de polifenóis,

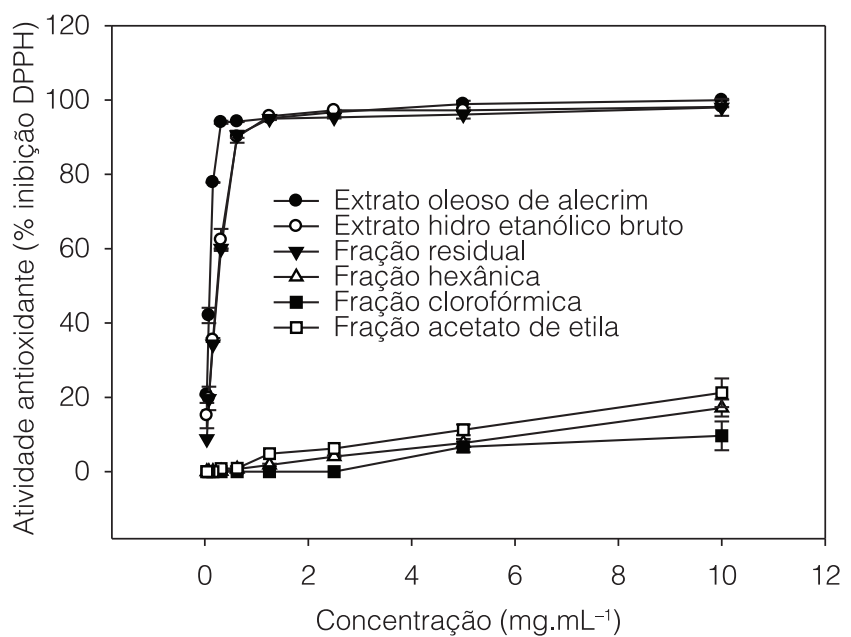

Figura 1. Atividade antioxidante do extrato hidroetanólico bruto de caqui, das frações e do extrato oleoso de alecrim pelo método de capacidade de sequestro do radical DPPH.

Tabela 1. Quantidade de compostos fenólicos totais e valores de $I C_{50}$ do extrato hidroetanólico bruto de caqui, das frações e do extrato oleoso de alecrim.

\begin{tabular}{lcc} 
& $\begin{array}{c}\text { Compostos fenólicos totais } \\
\text { (mg GAE.100 } \mathbf{~ m}^{-1} \text { ) }\end{array}$ & $\begin{array}{c}\text { DPPH IC }_{50} \\
\left.\mathbf{( m g}_{\mathbf{m}} \mathbf{m L}^{-1}\right)\end{array}$ \\
Extrato oleoso de alecrim & $4.311,94^{\star} \pm 30,35^{\star \star \star}$ & $0,09667 \pm 0,00577^{\mathrm{a}}$ \\
Extrato hidroetanólico bruto & $1.277,94 \pm 43,20^{\mathrm{b}}$ & $0,2467 \pm 0,01528^{\mathrm{b}}$ \\
Fração residual & $1.231,23 \pm 30,48^{\mathrm{b}}$ & $0,2567 \pm 0,005774^{\mathrm{b}}$ \\
Fração hexânica & $17,60 \pm 2,19^{\mathrm{c}}$ & $>10$ \\
Fração clorofórmica & $11,48 \pm 0,723^{\mathrm{c}}$ & $>10$ \\
Fração acetato de etila & $37,24 \pm 6,63^{\mathrm{c}}$ & $>10$ \\
\hline
\end{tabular}

*Valor de compostos fenólicos para extrato oleoso de alecrim expresso em mg GAE.100 g ${ }^{-1} \cdot{ }^{*}$ Valores médios \pm desvio padrão, com letras diferentes na mesma coluna são significativamente diferentes pelo teste de Tukey $(p<0,05)$. $>10$ : valor de IC ${ }_{50}$ não calculado para as frações que promoveram inibição dos radicais livres DPPH inferior a 50\%, até a maior concentração testada, ou seja, de $10 \mathrm{mg}^{\mathrm{mL}} \mathrm{m}^{-1}$. 
Atividade antioxidante e antimicrobiana in vitro de extratos de caqui (Diospyros kaki L.) cv. Rama Forte

MILANI, L.I.G. et al.

flavonoides e ácido ascórbico dos extratos. Chun et al. (2003) também verificaram que a capacidade antioxidante dos extratos de ameixa variou proporcionalmente aos teores de polifenóis e flavonoides. No entanto, a soma das atividades antioxidantes de cada constituinte do extrato foi menor que a capacidade antioxidante total, caracterizando o efeito sinérgico de diversos constituintes dos extratos que não foram quantificados.

Os resultados obtidos no teste de capacidade de sequestro de radicais livres DPPH são apresentados na Figura 1, na qual se observa que o porcentual antioxidante aumentou com o aumento da concentração do extrato hidroetanólico bruto de caqui e da fração residual até atingir a atividade antioxidante próxima a 100\%. Na concentração de $1,25 \mathrm{mg} \cdot \mathrm{mL}^{-1}$, ocorreu o consumo de mais que $94 \%$ do radical DPPH (Figura 1). O extrato oleoso de alecrim, usado neste trabalho como controle positivo, promoveu o mesmo efeito anteriormente citado, mas em concentração inferior $\left(0,3125 \mathrm{mg} \cdot \mathrm{mL}^{-1}\right)$. Em contrapartida, nas frações de acetato de etila, na fração clorofórmica e na fração hexânica, o consumo do radical DPPH se situou abaixo de $22 \%$ na maior concentração testada, ou seja, $10 \mathrm{mg} \cdot \mathrm{mL}^{-1}$ (Figura 1).

A planta Ginkgo biloba é uma planta considerada com alta atividade antioxidante e apresentou um $I_{50}$ de 0,04072 $\mathrm{mg} \cdot \mathrm{mL}^{-1}$, em experimento conduzido por Mensor et al. (2001). Tal valor demonstra que o extrato hidroetanólico bruto de caqui $\left(\mathrm{IC}_{50} 0,2467 \mathrm{mg} \cdot \mathrm{mL}^{-1}\right)$ e a fração residual $\left(\mathrm{IC}_{50} 0,2567 \mathrm{mg} \cdot \mathrm{mL}^{-1}\right)$ apresentam menor atividade antioxidante quando comparada ao extrato oleoso de alecrim $\left(\mathrm{IC}_{50} 0,09667 \mathrm{mg} \cdot \mathrm{mL}^{-1}\right)$ e ao extrato da Ginkgo biloba.

Os resultados obtidos por Pereira (2009) para o $\mathrm{IC}_{50}$, utilizando-se o método do DPPH, para o BHA (Butil Hidroxianisol), a catequina, o ácido gálico, o extrato de chá verde $\left(\right.$ Danisco $\left.{ }^{\circledR}\right)$, o extrato de erva mate, a mistura de extrato de erva-mate e marcela, e para o extrato de marcela foram de 0,0149, 0,0107, 0,0060, 0,34, 1,32, 1,90 e $5,26 \mathrm{mg} \cdot \mathrm{mL}^{-1}$, respectivamente. Apesar de os valores de $I \mathrm{C}_{50}$ do extrato hidroetanólico bruto de caqui e da fração residual serem maiores ao valor de $\mathrm{IC}_{50}$ do extrato oleoso de alecrim, os mesmos situaram-se abaixo do valor obtido pelo referido autor para o extrato de chá verde. Note-se que, assim como o extrato oleoso de alecrim, o extrato de chá verde está disponível comercialmente para uso como antioxidante natural. Demonstra-se, dessa forma, que o extrato hidroetanólico bruto de caqui e a fração residual apresentam possibilidade de serem aplicados em alimentos, merecendo estudos mais avançados nesse sentido.

Na Figura 2, pode-se observar o halo de inibição do crescimento microbiano frente ao disco impregnado com cloranfenicol $30 \mu \mathrm{g}(\mathrm{C}+)$, que foi utilizado como controle positivo no teste de difusão em disco. $\mathrm{O}$ extrato

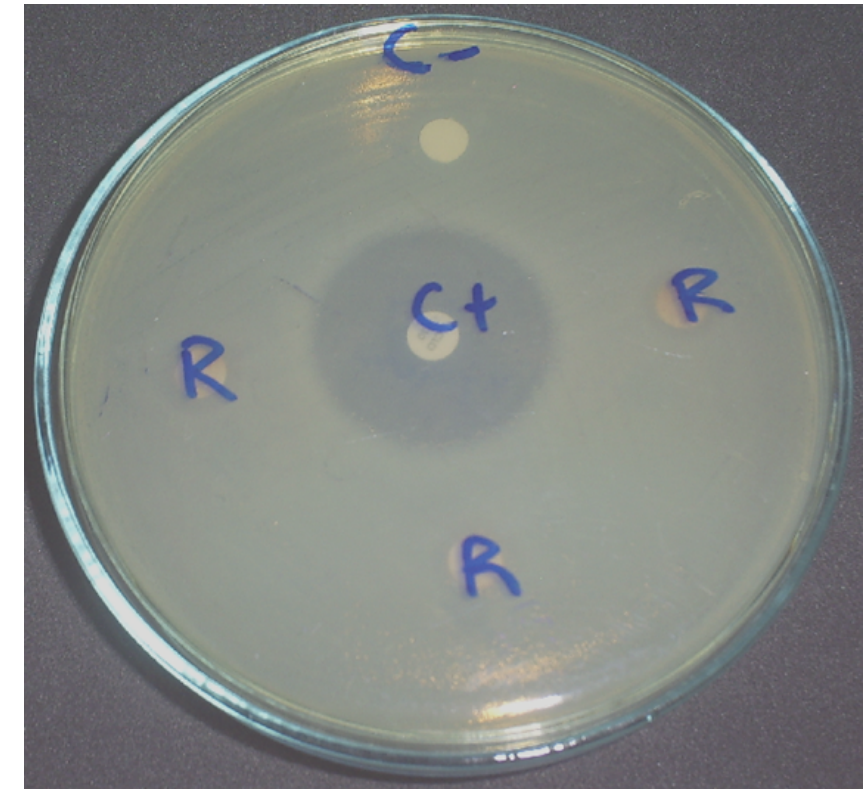

Figura 2. Placa de Petri com halo de inibição do crescimento microbiano frente ao disco impregnado com cloranfenicol $30 \mu \mathrm{g}$ $(\mathrm{C}+)$, discos com o extrato em 3 repetições $(\mathrm{R})$ e disco com água destilada (controle negativo, C-).

hidroetanólico bruto de caqui, as frações hexânica, clorofórmica, de acetato de etila e a fração residual não demonstraram atividade antimicrobiana sobre os microrganismos segundo o teste de difusão em disco (dados não apresentados). Em experimento conduzido por Taguri et al. (2006), no qual foi testada a atividade antibacteriana de 22 polifenóis puros ou parcialmente purificados, e de 26 extratos de plantas contra vários microrganismos (Gram-positivos, Gram-negativos, aeróbios, anaeróbios estritos e anaeróbios facultativos), o extrato de folhas de Diospyros kaki apresentou, em média, atividade antibacteriana fraca.

O resultado obtido no teste de difusão em disco sugere ausência de atividade antimicrobiana das substâncias presentes no extrato hidroetanólico bruto de caqui e nas frações, ou pequena concentração das mesmas, não atingindo a concentração inibitória mínima para os microrganismos em teste.

\section{Conclusões}

Nas condições deste estudo, o extrato hidroetanólico bruto de caqui cultivar Rama Forte e sua fração residual apresentaram maior teor de compostos fenólicos que as demais frações testadas, além de a atividade de eliminação do radical DPPH ser também superior, sugerindo que os compostos fenólicos tiveram significativa contribuição na atividade antioxidante. Logo, sugere-se que o extrato hidroetanólico bruto de caqui cultivar Rama Forte e a fração residual apresentam possibilidade de serem aplicados em alimentos, merecendo estudos mais avançados nesse sentido. 
Atividade antioxidante e antimicrobiana in vitro de extratos de caqui (Diospyros kaki L.) cv. Rama Forte MILANI, L.I.G. et al.

O extrato hidroetanólico bruto de caqui e as frações hexânica, clorofórmica, de acetato de etila e a fração residual não apresentaram atividade antimicrobiana contra as bactérias testadas.

\section{Referências}

AHN, J.; GRÜN; I. U.; MUSTAPHA, A. Effects of plant extracts on microbial growth, color change, and lipid oxidation in cooked beef. Food Microbiology, London, v. 24, n. 1, p. 7-14, 2007. http://dx.doi.org/10.1016/j.fm.2006.04.006

AMAROWICZ, R.; PEGG, R. B.; RAHIMI-MOGHADDAM, P.; BARL, B.; WEIL, J. A. Free-radical scavenging capacity and antioxidant activity of selected plant species from the Canadian prairies. Food Chemistry, London, v. 84, p. 551-562, 2004. http://dx.doi.org/10.1016/S0308-8146(03)00278-4

ASOLINI, F. C.; TEDESCO, A. M.; CARPES, S. T. Atividade antioxidante e antimicrobiana dos compostos fenólicos dos extratos de plantas usadas como chás. Brazilian Journal of Food Technology, Campinas, v. 9, n. 3, p. 209-215, 2006.

CAETANO, A. C. S.; MELO, E. A.; LIMA, V. L. A. G.; ARAUJO, C. R. Extração de antioxidantes de resíduos agroindustriais de acerola. Brazilian Journal of Food Technology, Campinas, v. 12, n. 2, p. 155-160, 2009. http://dx.doi.org/10.4260/ BJFT2009800900006

CHEN, X. N.; FAN, J. F.; YUE, X.; WU, X. R.; LI, L. T. Radical scavenging activity and phenolic compounds in persimmon (Diospyros kaki L. cv. Mopan). Journal of Food Science, Chicago, v. 73, n. 1, p. 24-28, 2008. http://dx.doi.org/10.1111/ j.1750-3841.2007.00587.x

CHOI, C. W.; KIM, S. C.; HWANG, S. S.; CHOI, B. K.; AHN, H. J.; LEE, M. Y.; PARK, S. H.; KIM, S. K. Antioxidant activity and free radical scavenging capacity between Korean medicinal plants and flavonoids by assay-guided comparison. Plant science, Davis, v. 163, p. 1161-1168, 2002. http://dx.doi.org/10.1016/ S0168-9452(02)00332-1

CHUN, O. K.; KIM, O. D.; MOON, H. Y.; KANG, H. G.; LEE, C. $Y$. Contribution of individual polyphenolics to total antioxidant capacity of plums. Journal Agricultural and Food Chemistry, Washington, v. 51, p. 7240-7245, 2003. http://dx.doi.org/10.1021/ jf0343579

COSTA NETO, P. L. O. Estatística. São Paulo: Edgard Bluches, 1977. 264 p.

FOGLIANO, V.; VERDE, V.; RANDAZZO, G.; RITIENI, A. Method for measuring antioxidant activity and its application to monitoring the antioxidant capacity of wines. Journal Agricultural and Food Chemistry, Washington, v. 47, p. 10351040, 1999. http://dx.doi.org/10.1021/jf980496s

GAIO, I. Atividade Antimicrobiana e Antioxidante In vitro e em Salame Tipo Italiano do Óleo Essencial de Manjericão (Ocimum basilicum L.). 2008. 139 f. Dissertação (Mestrado em
Engenharia de Alimentos)-Universidade Regional Integrada do Alto Uruguai e das Missões, Erechim, 2008.

GORINSTEIN, S.; ZACHWIEJA, Z.; FOLTA, M.; BARTON, J. P.; PIOTROWICZ, M. Z.; ZEMSER, M.; WISZ, M.; TRAKHTENBERG, S.; BELLOSO, O. M. Comparative Contents of dietary fiber, total phenolics, and minerals in Persimmons and apples. Journal Agricultural and Food Chemistry, Washington, v. 49, p. 952-957, 2001. http://dx.doi.org/10.1021/jf000947k

GU, H. F.; LI,C. M.; XU, Y. J.; HU, F. W.; CHEN, M. H.; WAN, Q. H. Structural features and antioxidant activity of tannin from persimmon pulp. Food Research International, Ontario, v. 41, n. 2, p. 208-217, 2008. http://dx.doi.org/10.1016/j. foodres.2007.11.011

KATSUBE, T.; TABATA, H.; OHTA, Y.; YAMASAKI, Y.; ANUURAD, E.; SHIWAKU, K.; YAMANE, Y. Screening for antioxidant activity in edible plant products: comparison of low-density lipoprotein oxidation assay, DPPH radical scavenging assay, and FolinCiocalteu assay. Journal of Agricultural and Food Chemistry, Washington, v. 52, n. 8, p. 2391-2396, 2004. http://dx.doi. org/10.1021/jf035372g

MENSOR, L. L.; MENEZES, F. S.; LEITÃO, G. G.; REIS, A. S.; SANTOS, T. C.; CINTIA, S.; COUBE, C. S.; LEITÃO, S. G. Screening of Brazilian plant extracts for antioxidant activity by the use of DPPH free radical method. Phytotherapy Research, Massachusetts, v. 15, n. 2, p. 127-130, 2001. HTTP://dx.doi. org/10.1002/ptr.687

MILANI, L. I. G.; TERRA, N. N.; FRIES, L. L. M.; REZER, A. A. S.; SILVA, L. S.; CAVALHEIRO, C. V. Avaliação da atividade antimicrobiana de extratos de caqui (Diospyros kaki, L.) cv. Quioto. In: CONGRESO ARGENTINO DE CIENCIA Y TECNOLOGIA DE ALIMENTOS - CYTAL ${ }^{\circledR}, 7$., 2009, Concordia, Argentina. Anais.. Entre Ríos: Asociación Argentina de Tecnologos Alimentários, Facultad de Ciencias de la Alimentación, 2009. 1 CD-ROM.

MILANI, L. I. G.; TERRA, N. N.; FRIES, L. L. M.; REZER, A. P. S.; FERREIRA, S. F.; CICHOSKI, A. J.; VALENTE, C. R. F. Oxidação lipídica, características sensoriais e cor da carne de frango adicionada de extratos de caqui (Diospyros kaki, L.) e submetida a tratamento térmico. Brazilian Journal of Food Technology, Campinas, v. 13, n. 4, p. 242-250, 2010. http:// dx.doi.org/10.4260/BJFT2010130400033

NACIONAL COMMITTEE FOR CLINICAL LABORATORY STANDARDS - NCCLS. Performance Standards for Antimicrobial Disk Susceptibility Tests. 8. ed. Wayne: NCCLS, 2003. 58 p. NCCLS document M2-A8.

PARK, Y. S.; Y. S.; JUNG, S. T.; KANG, S. G.; DELGADO-LICON, E.; AYALA, A. L. M.; TAPIA, M. S.; MARTIN-BELLOSO, O.; TRAKHTENBERG, S.; GORINSTEIN, S. Drying of persimmons (Diospyros kaky L.) and the following changes in the studied bioactive compounds and the total radical scavenging activities. Food Science and Technology - LWT, Zurich, v. 39, n. 7, p. 748-755, 2006. http://dx.doi.org/10.1016/j.lwt.2005.05.014 
Atividade antioxidante e antimicrobiana in vitro de extratos de caqui (Diospyros kaki L.) cv. Rama Forte

MILANI, L.I.G. et al.

PEREIRA, M. G. Aplicação de Antioxidantes Naturais em Carne Mecanicamente Separada (CMS) de Ave. 2009. 125 f. Dissertação (Mestrado em Ciência e Tecnologia dos Alimentos)Universidade Federal de Santa Maria, Santa Maria, 2009.

RAMIREZ-TORTOZA, C.; ANDERSEN, O. M.; GARDNER, P. T.; MORRICE, P. C.; WOOD, S. G.; DUTHIE, S. J.; COLLINS, A. R.; DUTHIE, G. G. Anthocyanin-rich extract decreases indices of lipid peroxidation and DNA damage in vitamin E depleted rats. Free Radical Biology and Medicine, San Diego, v. 46, p. 10331037, 2001. http://dx.doi.org/10.1016/S0891-5849(01)00618-9

ROSSO, V. V. Composição de Carotenoides e Antocianinas em Acerola: Estabilidade e Atividade Antioxidante em SistemasModelo de Extratos Antociânicos de Acerola e de Açaí. 2006. 136 f. Dissertação (Mestrado em Ciência e Tecnologia dos Alimentos)-Faculdade de Engenharia de Alimentos, Universidade Estadual de Campinas, Campinas, 2006.

SIMÕES, C. M. O. SCHENKEL, E. P.; GOSMANN, G.; MELLO, J. C. P.; MENTZ, L. A.; PETROVICK, P. R. Farmacognosia da planta ao medicamento. 3. ed. rev. Porto Alegre: Editora da UFRGS; Florianópolis: Editora da UFSC, 2001. 833 p.

SINGLETON, V. L.; ORTHOFER, R.; LAMUELA-RAVENTOS, R. M. Analysis of total phenols and other oxidation substrates and antioxidants by means of Folin-Ciocalteu reagent. Methods in Enzymology, Pasadena, v. 299, p. 152-178, 1999. http://dx.doi. org/10.1016/S0076-6879(99)99017-1

SOUSA, C. M.; SILVA, H. R.; VIEIRA-JUNIOR, G. M.; AYRES, M. C. A.; COSTA, C. L. C.; ARAÚJO, D. S.; CAVALCANTE, L. C. D.;
BARROS, E. D. S.; ARAÚJO, P. B. M.; BRANDÃO; M. S.; CHAVES, M. Fenóis totais e atividade antioxidante de cinco plantas medicinais. Química Nova, São Paulo, v. 30, n. 2, p. 351-355, 2007. http://dx.doi.org/10.1590/S0100-40422007000200021

SUZUKI, T.; SOMEYA, S.; HU, F.; HU, F.; TANOKURA, M. Comparative study of catechin compositions in five Japanese persimmons (Diospyros kaki). Food Chemistry, London, v. 93, n. 1, p. 149-152, 2005. http://dx.doi.org/10.1016/j. foodchem.2004.10.017

TAGURI, T.; TAKASHI, T.; KOUNO, I. Antibacterial spectrum of plant polyphenols and extracts depending upon hydroxyphenyl structure. Biological \& Pharmaceutical Bulletin, Japão, v. 29, n. 11, p. 2226-2235, 2006.

VEBERIC, R.; JURHAR, J.; MIKULIC-PETKOVSEK, M.; STAMPAR, F.; SCHMITZER, V. Comparative study of primary and secondary metabolites in 11 cultivars of persimmon fruit (Diospiros kaki L.). Food Chemistry, London, v. 119, n. 2, p. 477-483, 2010. http:// dx.doi.org/10.1016/j.foodchem.2009.06.044

VELIOGLU, Y. S.; NAZZA, G.; GAO, L.; OOMAH, B. D. Antioxidant activity and total phenolics in selected fruits, vegetables, and grain products. Journal of Agricultural and Food Chemistry, Washington, v. 46, n. 10, p. 4113-4117. 1998. http://dx.doi. org/10.1021/jf9801973

WANG, H.; CAO, G.; PRIOR, R. L. Oxygen radical absorbing capacity of anthocyanins. Journal of Agricultural and Food Chemistry, Washington, v. 45, p. 304-309, 1997. http://dx.doi. org/10.1021/jf960421t 